\title{
Survival after Lung Metastasectomy in Colorectal Cancer Patients with Previously Resected Liver Metastases
}

\author{
Michel Gonzalez • John Henri Robert • Nermin Halkic • \\ Gilles Mentha • Arnaud Roth - Thomas Perneger • \\ Hans Beat Ris · Pascal Gervaz
}

Published online: 14 December 2011

(C) Société Internationale de Chirurgie 2011

\begin{abstract}
Background Resection of hepatic metastases is indicated in selected stage IV colorectal cancer (CRC) patients. A minority will eventually develop pulmonary metastases and may undergo lung surgery with curative intent. The aims of the present study were to assess clinical outcome and identify parameters predicting survival after pulmonary metastasectomy in patients who underwent prior resection of hepatic CRC metastases.

Methods We performed a retrospective analysis of 27 consecutive patients (median age 62 years; range: 33-75 years) who underwent resection of pulmonary
\end{abstract}

M. Gonzalez $(\bowtie) \cdot$ H. B. Ris

Department of Thoracic Surgery, Centre Hospitalier

Universitaire Vaudois, Rue du Bugnon 46, 1011 Lausanne,

Switzerland

e-mail: Michel.Gonzalez@chuv.ch

J. H. Robert

Department of Thoracic Surgery, Geneva University Hospital,

Geneva, Switzerland

N. Halkic

Department of Visceral Surgery, Centre Hospitalier

Universitaire Vaudois, Rue du Bugnon 46, 1011 Lausanne,

Switzerland

G. Mentha $\cdot$ P. Gervaz

Department of Visceral Surgery, Geneva University Hospital, Geneva, Switzerland

\author{
A. Roth \\ Department of Oncology, Geneva University Hospital, \\ Geneva, Switzerland \\ T. Perneger \\ Department of Biostatistics, Geneva University Hospital, \\ Geneva, Switzerland
}

metastases after previous hepatic metastasectomy from CRC in two institutions from 1996 to 2009. All patients underwent complete resection (R0) for both colorectal and hepatic metastases.

Results Median follow-up was 32 months (range: 3-69 months) after resection of lung metastases and 65 months (range: 19-146 months) after resection of primary CRC. Three- and 5-year overall survival rates after lung surgery were 56 and $39 \%$, respectively, and median survival was 46 months (95\% CI 35-57). Median diseasefree survival after pulmonary metastasectomy was 13 months (95\% CI 5-21). At the time of last follow-up, seven patients $(26 \%)$ had no evidence of recurrent disease and 6 of these 7 patients presented initially with a single lung metastasis.

Conclusions Resection of lung metastases from CRC patients may result in prolonged survival, even after previous hepatic metastasectomy. Yet, prolonged disease-free survival remains the exception, and seems to occur only in patients with a single lung lesion.

\section{Introduction}

Liver and lung are the most frequent sites of metastases from colorectal cancer (CRC). Up to $25 \%$ of colorectal cancer (CRC) patients initially present with metastatic disease, usually confined to the liver, and another $25 \%$ of patients will develop metachronous liver metastases after primary tumor resection [1, 2]. Pulmonary metastases develop in $8-10 \%$ of CRC patients, and may occur after previous liver metastases [3,4]. Although several novel chemotherapeutic and biological agents have been developed, surgery is considered the most effective therapy for selected patients with liver metastases [5]. Specialized 
centers have reported 5-year survival rates up to $50 \%$ after liver resection for CRC metastases [6, 7]. Similarly, surgical resection of synchronous or metachronous pulmonary metastases has gained increased acceptance. Since 2000, multiple series have investigated the outcome of CRC patients who underwent resection of lung metastasis, with 5 -year survival rates ranging from 24 to $68 \%$ [8-11].

However, the role of surgery is controversial for patients presenting with both hepatic and pulmonary metastases. In the literature, there are few series reporting the outcome of more than 30 patients with resection of both hepatic and pulmonary metastases [12-18]. In addition, these studies were conducted at a time when hepatectomy was rarely considered in patients with extensive liver metastasis and before the modern era of chemotherapeutic and biological agents. The aim of the present study was to assess the clinical outcome after pulmonary metastasectomy in patients who underwent prior resection of hepatic CRC metastases and to identify predictors for survival.

\section{Patients and methods}

We performed a retrospective analysis of all CRC patients who underwent pulmonary surgical resection with a curative intent in two different institutions (Geneva University Hospital and Lausanne University Hospital) in Switzerland. Among 70 patients with pulmonary metastases who underwent pulmonary metastasis resection, 27 patients had previously undergone resection of hepatic metastases. All of these patients were operated on since 1996 and they constitute the subject of this retrospective study. Lung surgery and liver metastases surgery were performed in the Thoracic Surgery Unit and in the Visceral Surgery Unit of both institutions. We included all patients with a histopathological diagnosis of colorectal adenocarcinoma metastatic to the lung who had undergone prior liver surgery.

The following parameters were recorded and considered for statistical analysis: (1) patient characteristics; (2) primary tumor characteristics (TNM stage, location, preoperative radiation therapy, adjuvant chemo-and/or chemotherapy); (3) characteristics of liver metastases (number and location, size of largest metastases, adjuvant chemotherapy, and extent of liver resection); (4) characteristics of lung metastases (number and size of the largest metastasis, type of resection [wedge, lobectomy or pneumonectomy], involvement of mediastinal lymph nodes, adjuvant chemotherapy, disease-free interval between primary tumor resection and development of lung metastases, and unilateral or bilateral distribution). The study was conducted in accordance with institutional guidelines of the Ethics Committee for Clinical Research of Geneva University Hospital and Lausanne University Hospital.
Eligibility for surgical resection of lung metastases from CRC after previous liver surgery was based on four criteria: (1) control of primary tumor considered as achieved; (2) absence of extrathoracic lesions at the time of lung surgery; (3) possibility to perform a complete resection (R0) of pulmonary metastases; and (4) adequate pulmonary reserve to tolerate the planned resection. Follow-up was performed in the Surgical Oncology Unit of both institutions, with repeated clinical examination and thoracoabdominal CT scan imaging once a year for 5 years to detect local or systemic tumor recurrence. In addition all patients underwent colonoscopy surveillance at 1,3 , and 5 years postcolectomy.

All patients received two to six cycles of chemotherapy before liver resection, using a combination of oxaliplatin $[\mathrm{O}]$, irinotecan (CPT-11[C]), 5-fluorouracil (5-FU) $[\mathrm{F}]$, and leucovorin $[\mathrm{L}]$, according to the following doses and schedule: oxaliplatin $70 \mathrm{mg} / \mathrm{m}^{2}$ on days 1 and 15 , irinotecan (CPT-11) $100 \mathrm{mg} / \mathrm{m}^{2}$ on days 8 and $22,5-\mathrm{FU} 2 \mathrm{~g} / \mathrm{m}^{2} / 24 \mathrm{~h}$ and leucovorin (LV) $30 \mathrm{mg}$ on days $1,8,15$, and 22, repeated every 5 weeks. Seven patients had a similar regimen, but with 5-FU/LV replaced with capecitabine (the oral prodrug of 5-FU) $800 \mathrm{mg} / \mathrm{m}^{2}$ per day from day 1 to day 28 . One patient received a standard treatment with capecitabine and oxaliplatin (capecitabine $2 \mathrm{~g} / \mathrm{m}^{2}$, oxaliplatin $130 \mathrm{mg} / \mathrm{m}^{2}$ day 1 , days $1-14$, repeated every 3 weeks). The response to chemotherapy was assessed after two to three cycles. Further evaluations were obtained according to the clinical response and surgical pattern of disease. More recently, patients were treated with the addition of bevacizumab (Avastin) and cetuximab (Erbitux) to complement the OCFL regimen.

\section{Statistical analysis}

The follow-up was complete for all patients. Frequency distributions were obtained for descriptive patient variables. Kaplan-Meier methods were used to examine relapse-free survival and overall survival. The association between tumor relapse and death was explored in a Cox proportional hazards model where relapse was a timedependent covariate: a patient switched from low-risk status to high-risk status at the time of the relapse (not at baseline). Simple Cox models were used to examine associations between patient characteristics and risk of death. Because of the low number of patients, no multivariate model was constructed. The analyses were performed with SPSS version 17 (SPSS, Chicago, IL). A $P$ value $<0.05$ was considered statistically significant.

\section{Results}

The study sample included 27 patients ( 14 men, 13 women) initially diagnosed with CRC who first underwent resection 
of liver metastases and then surgery for lung metastases. The median age at the time of lung surgery was 62 years (range: $33-75$ years). Primary tumor location was predominantly the left colon (14 patients) and the rectum (11 patients). Using the TNM classification, most patients presented initially with an advanced local tumor stage (stages III/IV: 18 patients). Less than half of patients presented initially with synchronous metastatic disease (M0: 17 patients, M1: 10 patients). The clinical stage at diagnosis was advanced for most patients (stage I: 2 patients; stage II: 7 patients; stage III: 8 patients and stage IV: 10 patients). The clinical, pathological, and surgical characteristics of the study population are summarized in Table 1.

The mode of development and the sequence of metastatic spread are summarized in Fig. 1. Interval between resection of primary tumor and that of liver metastases ranged from 0 to 50 months (median: 11 months). Liver

Table 1 Clinicopathological characteristics of 27 colorectal cancer (CRC) patients with resection of both hepatic and pulmonary metastases

\begin{tabular}{|c|c|c|}
\hline Parameters & $\begin{array}{l}\text { Number } \\
\text { of patients }\end{array}$ & Percen \\
\hline \multicolumn{3}{|l|}{ Gender } \\
\hline Male & 14 & 52 \\
\hline Female & 13 & 48 \\
\hline \multicolumn{3}{|l|}{ Age } \\
\hline$<60$ years & 11 & 41 \\
\hline$>60$ years & 16 & 59 \\
\hline \multicolumn{3}{|l|}{ Location of primary CRC } \\
\hline Colon & 16 & 59 \\
\hline Rectum & 11 & 41 \\
\hline \multicolumn{3}{|l|}{ T stage } \\
\hline $\mathrm{T} 1 / \mathrm{T} 2$ & 5 & 18 \\
\hline $\mathrm{T} 3 / \mathrm{T} 4$ & 22 & 82 \\
\hline \multicolumn{3}{|l|}{ Nodal status } \\
\hline No & 12 & 44 \\
\hline N1 & 8 & 30 \\
\hline $\mathrm{N} 2$ & 7 & 26 \\
\hline Metachronous metastasis & 10 & 37 \\
\hline \multicolumn{3}{|c|}{ Number of pulmonary metastases } \\
\hline 1 & 20 & 74 \\
\hline$>1$ & 7 & 26 \\
\hline \multicolumn{3}{|l|}{ Number of liver metastases } \\
\hline$<3$ & 19 & 70 \\
\hline$>3$ & 8 & 30 \\
\hline \multicolumn{3}{|l|}{ Type of liver resection } \\
\hline Wedge & 7 & 26 \\
\hline Segmentectomy & 11 & 41 \\
\hline Left hepatectomy & 2 & 7 \\
\hline Right hepatectomy & 7 & 26 \\
\hline
\end{tabular}

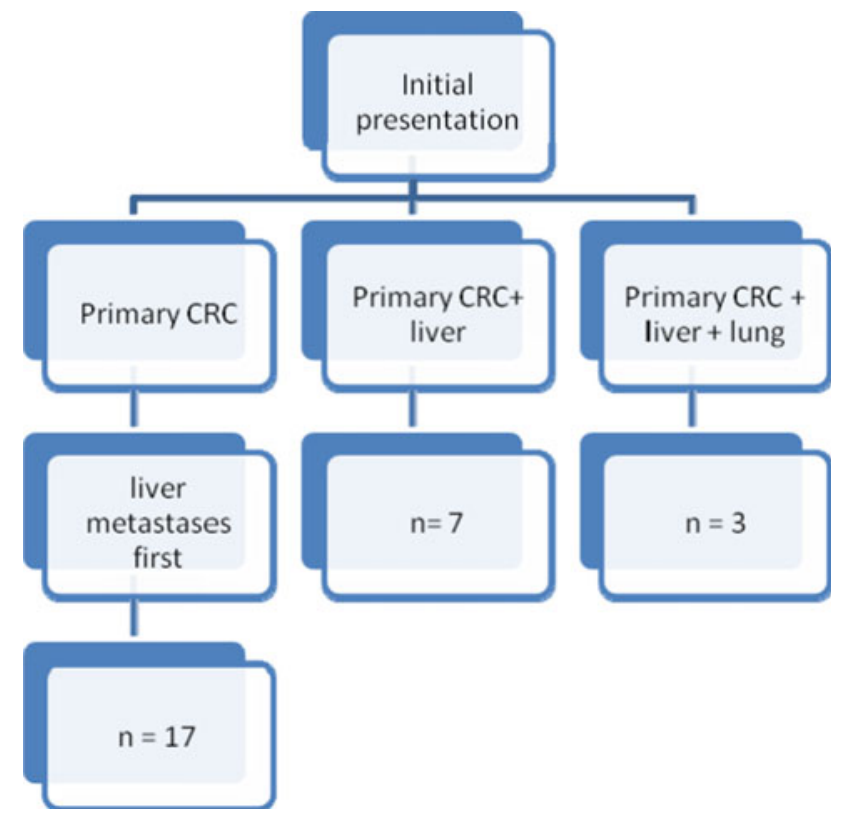

Fig. 1 Sequence of hepatic and pulmonary metastases after the diagnosis of colorectal cancer

locations were in the right lobe in 17 patients, in the left lobe in four patients and in both lobes in six patients. The median delay between primary tumor resection and surgery for lung metastasis was 32 months (range: 0-100 months). Twenty patients had a single lung metastasis; the others had between 2 and 7 metastases. The median size of the largest metastasis was $25 \mathrm{~mm}$ (range: 6-75 mm). The vast majority of patients $(74 \%)$ underwent pulmonary wedge resections as a major lung resection. No patient had simultaneous liver and pulmonary resection.

Follow-up was obtained for all patients until death (11 patients) or last visit (16 patients). The median duration of follow-up was 32 months (range: 3-69 months) after lung surgery. During this period, 20 patients had a relapse of the primary tumor, in the liver (5), lung (5), bone (4), brain (1), or multiple sites (5). Ten of the 20 patients who relapsed died, versus 1 of the 7 relapse-free patients. Occurrence of relapse was a strong predictor of death. In a proportional hazards model in which relapse was a timedependent covariate (i.e., the patient moved to the high risk group only at the time of the relapse), tumor relapse was associated with an almost nine-fold increase in the risk of death (relative hazard 8.9, 95\% CI 1.1-71.7). Three- and 5 -year overall survival rates after lung surgery were 56 and $39 \%$, respectively, and median survival was $46(95 \%$ CI 35-57) months (Fig. 2). Median disease-free survival after pulmonary metastasectomy was 13 (95\% CI 5-21) months (Fig. 3).

As an exploratory analysis, because of the small sample size, we examined patient characteristics that may be 


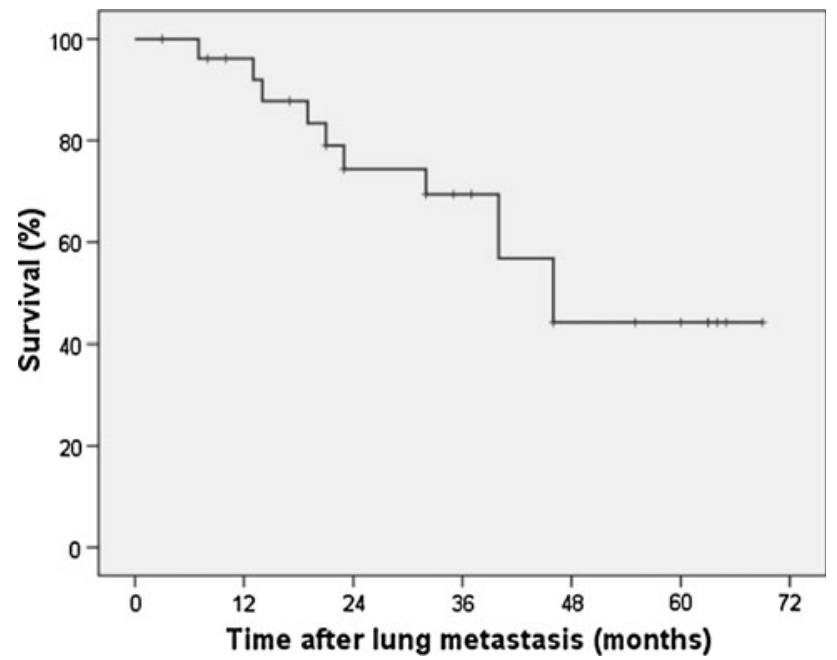

Fig. 2 Overall survival after lung metastasectomy

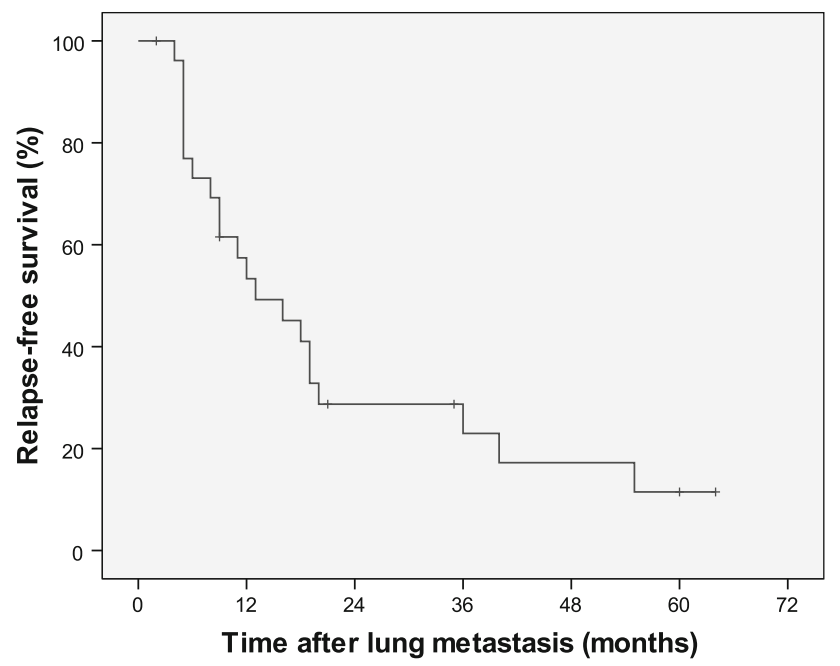

Fig. 3 Relapse-free survival of patients with lung metastases

associated with mortality (Table 2). Three parameters were associated with an average twofold increase in mortality: (1) age >60 years; (2) primary tumor stage III/IV; and (3) presence of multiple lung metastases, as opposed to a single metastasis (Fig. 4). None of these associations appeared, however, statistically significant.

\section{Discussion}

We report a series of 27 CRC patients treated with modern chemotherapy (oxaliplatin, irinotecan, and biologic agents), who underwent liver surgery after 1999, and then subsequent lung metastasectomy. Our data indicate that these patients may experience prolonged (median 46 months) survival. However, a majority $(74 \%)$ of
Table 2 Association between patient characteristics and risk of death

\begin{tabular}{|c|c|c|c|}
\hline Patient characteristics & $\begin{array}{l}\text { Deaths/ } \\
\text { patients }\end{array}$ & $\begin{array}{l}\text { Relative } \\
\text { hazard } \\
(95 \% \mathrm{CI})\end{array}$ & $P$ value \\
\hline Gender & & & 0.83 \\
\hline Male & $6 / 14$ & 1.0 (reference) & \\
\hline Female & $5 / 13$ & $1.1(0.3-3.8)$ & \\
\hline Age & & & 0.27 \\
\hline$<60$ years & $3 / 11$ & 1.0 (reference) & \\
\hline$\geq 60$ years & $8 / 16$ & $2.1(0.6-8.0)$ & \\
\hline Primary location & & & 0.78 \\
\hline Colon & $6 / 16$ & 1.0 (reference) & \\
\hline Rectum & $5 / 11$ & $1.2(0.4-3.9)$ & \\
\hline Tumor stage & & & 0.40 \\
\hline $1-2$ & $2 / 9$ & 1.0 (reference) & \\
\hline $3-4$ & $9 / 18$ & $1.9(0.4-9.0)$ & \\
\hline Time to first metastasis & & & 0.44 \\
\hline $0-6$ months & $7 / 14$ & $1.6(0.5-5.5)$ & \\
\hline$>6$ months & $4 / 13$ & 1.0 (reference) & \\
\hline $\begin{array}{l}\text { Time from liver metastasis } \\
\text { to lung metastasis }\end{array}$ & & & 0.49 \\
\hline 0-24 months & $5 / 16$ & $0.7(0.2-2.2)$ & \\
\hline$>24$ months & $5 / 11$ & 1.0 (reference) & \\
\hline Number of lung metastases & & & 0.38 \\
\hline 1 & $8 / 20$ & 1.0 (reference) & \\
\hline 2 or more & $3 / 7$ & $1.8(0.5-7.1)$ & \\
\hline $\begin{array}{l}\text { Size of largest lung } \\
\text { metastases }\end{array}$ & & & 0.94 \\
\hline$\leq 25 \mathrm{~mm}$ & $7 / 16$ & 1.0 (reference) & \\
\hline$>25 \mathrm{~mm}$ & $4 / 11$ & $1.0(0.3-3.6)$ & \\
\hline
\end{tabular}

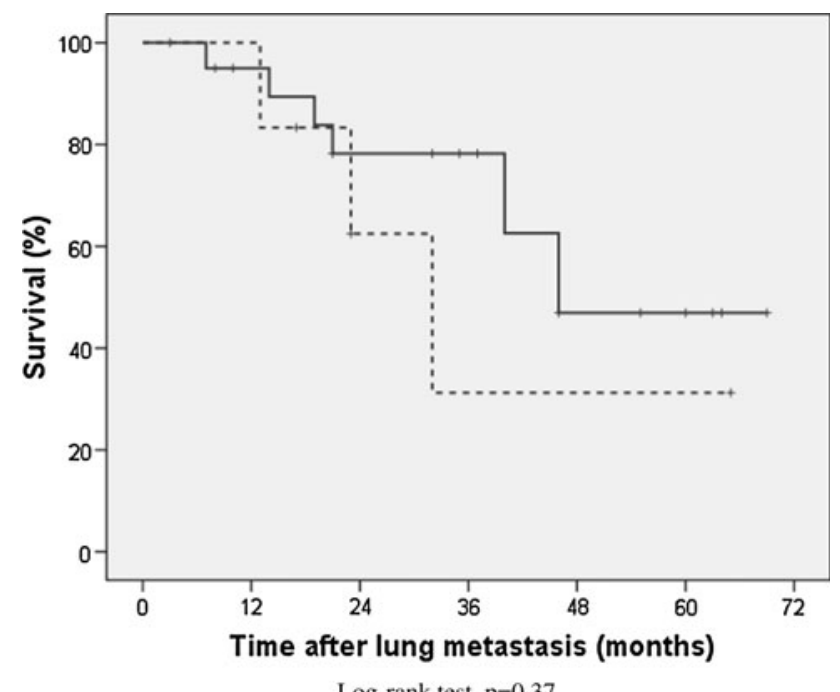

Log-rank test, $\mathrm{p}=0.37$

Fig. 4 Survival in patients with single (solid line) or multiple (dashed line) lung metastases 
patients developed tumor recurrence with short median relapse-free survival (13 months). Six of seven patients who were alive with no evidence of disease at last followup had a single isolated lung metastasis. This group of patients with limited CRC spread to the lung (a single lesion less than $2 \mathrm{~cm}$ in size) may benefit the most from pulmonary metastasectomy.

Surgical resection is rarely curative in CRC patients who subsequently develop both hepatic and pulmonary metastases: most clinicians rightfully consider that metastatic spread to more than one organ reflects the systemic nature of the disease. Yet, in selected cases, resections of pulmonary and hepatic metastases of CRC are increasingly considered as a curative option. In our series, as in others [12], this approach is now associated with median survival up to 4 years, even though long-term relapse-free survivals remain exceptional. The challenge is now to identify the group of patients which will benefit from this aggressive sequential surgical approach. Unfortunately, predictive factors for prolonged disease-free survival in these patients are yet to be defined.

Various parameters have been associated with prolonged survival in isolated pulmonary metastasectomy from CRC including: (1) a long disease-free interval [19-22]; (2) prethoracotomy carcinoembryonic antigen (CEA) level

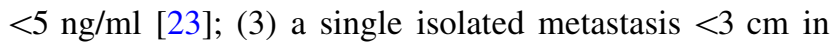
size [24]; and (4) the absence of thoracic lymph node invasion [25, 26]. In contrast, predictive prognostic factors after both liver and lung metastases resection of CRC have not been clearly defined in the literature. Miller et al. [12] reported in 2007 the largest series of patients and identified prognostic factors for improved survival: (1) diseasefree interval in-between metastases greater than 1 year, (2) single liver metastasis, and (3) age less than 55. Others reported that lung first metastases [15] and high CEA level before metastasectomy [13] were prognostic factors of worse outcome. In our series, mortality was increased by twofold in patients with primary tumor stages III or IV and presence of multiple lung metastases, but due to the small sample size, results were not statistically significant.

Five-year survival rates after first metastasectomy reported in various series ranged from 11 to $50 \%$ [12-18]. These different results are difficult to compare due to probably better patient selection in a long inclusion period and different tumor biology. Liver resection was generally performed before 2000 in selected patients before the improvement of perioperative care and surgical techniques. Our results did not differ from the literature with 5-year survival rate of $39 \%$ after lung metastasectomy. Interestingly, a recent series indicates that patients who underwent resection of both liver and lung colorectal metastases may experience longer survival than patients who underwent resection of liver metastases alone (5-year overall survival rates $50 \%$ vs. $40 \%$ ) [18].
In conclusion we report a series of highly selected CRC patients with both liver and lung metastases and who benefited from a modern chemotherapy regimen in addition to surgery with a curative intent in both metastatic locations. While resection of lung metastases from CRC may be compatible with prolonged survival (even when patients have undergone prior resection of liver metastases), it is clear that the majority of patients will experience a recurrence within 2 years after lung surgery and ultimately will die from colorectal cancer. We observed that 6 of 7 patients who were disease-free at the time of last follow-up presented with a single, small $(<2 \mathrm{~cm})$ lung metastasis. Clearly, CRC patients with this type of disease extension are good candidates for pulmonary resection, even when they have previously undergone resection of liver metastases.

\section{References}

1. Andres A, Majno PE, Morel P et al (2008) Improved long-term outcome of surgery for advanced colorectal liver metastases: reasons and implications for management on the basis of a severity score. Ann Surg Oncol 15:134-143

2. Fong Y, Fortner J, Sun RL et al (1999) Clinical score for predicting recurrence after hepatic resection for metastatic colorectal cancer: analysis of 1001 consecutive cases. Ann Surg 230:309-318

3. Fiorentino F, Hunt I, Teoh K et al (2010) Pulmonary metastasectomy in colorectal cancer: a systematic review and quantitative synthesis. J R Soc Med 103:60-66

4. Landes U, Robert J, Perneger T et al (2010) Predicting survival after pulmonary metastasectomy for colorectal cancer: previous liver metastases matter. BMC Surg 10:17

5. Robert JH, Ambrogi V, Mermillod B et al (1997) Factors influencing long-term survival after lung metastasectomy. Ann Thorac Surg 63:777-784

6. Belghiti J, Hiramatsu K, Benoist S et al (2000) Seven hundred forty-seven hepatectomies in the 1990s: an update to evaluate the actual risk of liver resection. J Am Coll Surg 191:38-46

7. Rees M, Tekkis PP, Welsh FK et al (2008) Evaluation of longterm survival after hepatic resection for metastatic colorectal cancer: a multifactorial model of 929 patients. Ann Surg 247: $125-135$

8. Pfannschmidt J, Dienemann H, Hoffmann H (2007) Surgical resection of pulmonary metastases from colorectal cancer: a systematic review of published series. Ann Thorac Surg 84:324-338

9. Riquet M, Foucault C, Cazes A et al (2010) Pulmonary resection for metastases of colorectal adenocarcinoma. Ann Thorac Surg 89:375-380

10. Lee WS, Yun SH, Chun HK et al (2007) Pulmonary resection for metastases from colorectal cancer: prognostic factors and survival. Int J Colorectal Dis 22:699-704

11. Watanabe K, Nagai K, Kobayashi A et al (2009) Factors influencing survival after complete resection of pulmonary metastases from colorectal cancer. Br J Surg 96:1058-1065

12. Miller G, Biernacki P, Kemeny NE et al (2007) Outcomes after resection of synchronous or metachronous hepatic and pulmonary colorectal metastases. J Am Coll Surg 205:231-238

13. Hendrick JR, Miller DL, Nagorney DM et al (2001) Surgical treatment of hepatic and pulmonary metastases from colon cancer. Ann Thorac Surg 71:975-979 
14. Regnard JF, Grunenwald D, Spaggiari L et al (1998) Surgical treatment of hepatic and pulmonary metastases from colorectal cancers. Ann Thorac Surg 66:214-218

15. Neeff H, Horth W, Makowiec F et al (2009) Outcome after resection of hepatic and pulmonary metastases of colorectal cancer. J Gastrointest Surg 13:1813-1820

16. Kobayashi K, Kawamura M, Ishihara T (1999) Surgical treatment for both pulmonary and hepatic metastases from colorectal cancer. J Thorac Cardiovasc Surg 118:1090-1096

17. Shah SA, Haddad R, Al-Sukhni W et al (2006) Surgical resection of hepatic and pulmonary metastases from colorectal carcinoma. J Am Coll Surg 202:468-475

18. Brouquet A, Vauthey JN, Contreras CM et al (2011) Improved survival after resection of liver and lung colorectal metastases compared with liver-only metastases: a study of 112 patients with limited lung metastatic disease. J Am Coll Surg 213:62-69

19. Rena O, Casadio C, Viano F et al (2002) Pulmonary resection for metastases from colorectal cancer: factors influencing prognosis. Twenty-year experience. Eur J Cardiothorac Surg 21: 906-912

20. Takakura Y, Miyata Y, Okajima M et al (2010) Short disease-free interval is a significant risk factor for intrapulmonary recurrence after resection of pulmonary metastases in colorectal cancer. Colorectal Dis 12:e68-e75

21. Lin BR, Chang TC, Lee YC et al (2009) Pulmonary resection for colorectal cancer metastases: duration between cancer onset and lung metastasis as an important prognostic factor. Ann Surg Oncol 16:1026-1032

22. Onaitis MW, Petersen RP, Haney JC et al (2009) Prognostic factors for recurrence after pulmonary resection of colorectal cancer metastases. Ann Thorac Surg 87:1684-1688

23. Iizasa T, Suzuki M, Yoshida S et al (2006) Prediction of prognosis and surgical indications for pulmonary metastasectomy from colorectal cancer. Ann Thorac Surg 82:254-260

24. Vogelsang H, Haas S, Hierholzer C et al (2004) Factors influencing survival after resection of pulmonary metastases from colorectal cancer. Br J Surg 91:1066-1071

25. Pfannschmidt J, Muley T, Hoffmann H et al (2003) Prognostic factors and survival after complete resection of pulmonary metastases from colorectal carcinoma: experiences in 167 patients. J Thorac Cardiovasc Surg 126:732-739

26. Welter S, Jacobs J, Krbek T et al (2007) Prognostic impact of lymph node involvement in pulmonary metastases from colorectal cancer. Eur J Cardiothorac Surg 31:167-172 